\title{
Interventions for Caregivers of People with Dementia in Greece
}

\author{
Karagiozi K ${ }^{*}$, Margaritidou P1, Egkiazarova $\mathbf{M}^{1}$, \\ Toumpalidou M', Makri $\mathbf{M}^{1}$ and Tsolaki $\mathbf{M}^{1,2}$ \\ ${ }^{1}$ Alzheimer Hellas, Thessaloniki, Greece \\ 23rd Department of Neurology, Faculty of Medicine, \\ Aristotle University of Thessaloniki, Greece \\ *Corresponding author: KaragioziK, Alzheimer \\ Hellas, 13 PetrouSindikastr., P.C. 54643, Thessaloniki, \\ Greece
}

Received: August 01, 2017; Accepted: August 24, 2017; Published: August 31, 2017

\begin{abstract}
Recent researches have shown that intervention programs are essential in order to facilitate the caregivers' role and improve their emotional state and quality of life. This study presents the therapeutic interventions that are provided in the Day Center for Caregivers of Greek Association of Alzheimer Disease and Related Disorders (Alzheimer Hellas). Day Center for Caregivers is established in order to give psycho-educational and psychological support to dementia caregivers. Participating in therapeutic interventions caregivers learn to take care of the people with dementia and themselves physically and emotionally.
\end{abstract}

Keywords: Caregivers; Dementia; Interventions; Day center

\section{Introduction}

Dementia is considered to be one of the major public health challenges worldwide. Nowadays, it affects more than 47 million people all over the world and it is on the increase due to the aging of the population [1]. Quality of life of the patients with dementia $(\mathrm{PwD})$ and their caregivers as well as the society in general are also seriously affected [2]. In generally, dementia demands high levels of care, most of which is provided by family or informal caregivers. Without their help, PwD would have poorer quality of life and thus institutionalization will be increased more quickly. Moreover, national economies would be strongly affected by the increasing demographic tendency [3].

Caregiving does bring personal gains and feeling of fulfillment. However, according to the research findings, family caregivers are extremely vulnerable [4]. They are usually members of the family who undertake the role out of necessity or obligation [5] and also, their role is extremely critical [6]. They are people who are indispensable to maximize well-being of their care recipient, since caregivers are best placed to identify their personal needs and desires with a unique way and thus emerge the person-centered care like the most significant [7]. The caregiver is commonly female, of rather low education, living with the care recipient, spends a lot of hours caregiving and thus, they seem to have their emotional, physical, social and financial needs unfulfilled [8]. In line with other research, caregivers often report high levels of stress which affects them by feelings of low self-esteem, low sense of well-being, depression, sense of burden, compromised physical health and sometimes premature death $[9,10,11]$. Apart from psychological problems, social relationships change and psychosocial health may cause immunological dysfunctions to caregivers [12]. Consequently, despite the fact that some caregivers experience feelings of personal gain and satisfaction, they need psychosocial and instrumental support to cope with caregiving $[9,13]$.

Over the last decades, in order to support caregivers, numerous psychosocial interventions, necessary for the support of the caregivers, have been developed [14]. Systematic reviews and meta-analyses nominate mixed results with respect to the effectiveness of these interventions on caregiver mood or burden [15,16]. Self-efficacy, coping, mastery, depressive symptoms, emotional distress, burden and quality of life are some of the outcomes referred as positive effects and are major endpoints [14]. Also, according to other studies, most of the heterogeneous interventions have been evaluated and found to be effective to some extent [7]. Empirical evidence of effectiveness has been indicated on the caregiver's mental health, delay of deterioration of illness condition and institutionalization of the care recipient [12].

Interventions designed to help caregivers have been developed in various forms, such as individualized, family or group programs, and in various contexts, such as face to face interventions in Care Center or home meetings, telephone, videophones and web-based services. Multiple helping strategies such as information giving, training on problem solving skills, social support and techniques to better manage with stress in order to improve the caregivers' knowledge and skills should be involved in these interventions $[3,12,15,17]$.

The Greek Association of Alzheimer Disease and Relative Disorders (Alzheimer Hellas) is a non for profit organization that was founded in 1995. Today, Alzheimer Hellas operates 2 Day Care Centers in Thessaloniki and has over 6.000 members. The first Day Care Center for PwD, encompasses a Day center for caregivers and a home care unit, was established in 2007 and the second in 2009. The goals of the Greek Association of Alzheimer's Disease is 1) the early diagnosis of dementia by scientists, 2) the promotion of research, 3) the education and training for all the stakeholders, 4) the development of Care Units for patients with Alzheimer's Disease, 5) the provision of useful information and advice (24hour help-line) on dementia problems (caring, legal or financial issues), 6) the presentation of lectures by health professionals and informal caregivers, covering all aspects of Alzheimer Disease and (7) the development of professional seminars.

Day centers for caregivers were established in order to give support and counselling to caregivers concerning the care of the PwD. From 2008 , more than 3.000 caregivers have participated in a lot of different interventions. The supportive interventions have been developed in various forms, such as face to face and online form, in order to meet the
J Fam Med - Volume 4 Issue 5 - 2017

ISSN : 2380-0658 | www.austinpublishing group.com

Karagiozi et al. (C) All rights are reserved
Citation: Karagiozi K, Margaritidou P, Egkiazarova M, Toumpalidou M, Makri M and Tsolaki M. Interventions for Caregivers of People with Dementia in Greece. J Fam Med. 2017; 4(5): 1125. 
needs of the population of the caregivers. The interventions provided to caregivers are (a) psycho-educational group, (b), online psychoeducational group, (c) family support intervention, (d)psychological support group, (e) support group using literature entitled "Listen to my story", (f) "theater of the oppressed", (g) relaxation intervention, (h) grief support group, and (i) community outreach: intervention for children entitled "Who I am grandpa?" and radio program "All about dementia".

\section{Interventions for Caregivers}

\section{A) Psycho-educational group}

Psycho-educational group program aims to provide information to caregivers regarding the disease and guidelines for more effective care. It helps caregivers in making difficult decisions that concern the care and the treatment of their care receivers and they learn to be flexible in the negotiation of alternative solutions [18]. According to Hsu et al. [19] caregivers may have sustained benefit of reducing burden, decreasing psychological morbidity and enhancing psychological wellbeing after attending a psycho-educational intervention.

Alzheimer Hellas provides a psycho-educational group intervention which consists of 24 weekly sessions, each lasting 60 minutes, for 6 months. In order to examine the effectiveness of this intervention, each participant is assessed before and after the 6-month period of the study. The scheduled topics of the lessons are a) general information about the disease (what is dementia, what are the types of dementia, risk and protective factors etc.), b) behavioral symptoms of dementia (types of behavioral symptoms, practical solutions, which non-pharmacological interventions are better etc.) and c) caregiver's wellness (what is the role of the caregiver, usual feelings in caregiving, the role of the family etc.). Participants are encouraged to be actively involved throughout the sessions by asking questions regarding patients or themselves, sharing their experiences and providing guidance and support to other caregivers.

\section{B) Online psycho-educational group}

Online psycho-educational intervention has been applied in order to face the problem of underutilization of traditional support services from caregivers. Health issues, transportation and time constraints were the reasons for non-participation in traditional support groups. According to Kales et al. [20] the available face to face interventions have been proved to be effective but only for a limited period of time, and they have also been found to be time consuming, which is limited to caregivers. Using online intervention, the caregivers can be in contact with other members while they can stay at their homes. This is an essential opportunity for Greek caregivers to engage in social interaction and support, as in most of the small towns, a professional help would be a real challenge to find. The online psycho-educational intervention is being provided via video conference group which has been created as a substitute for face to face psychotherapeutic interventions. According to Marzipali \& Garcia [5], video conference group showed more significant improvement in caregivers' wellbeing and lower stress response than the online support chat did.

The aim of online psycho-educational intervention is to educate caregivers about the disease, to provide a better treatment and to help participants to share their experiences and thoughts within the group.
Therefore, the intervention aims to reduce the anxiety and depression symptoms and the sense of burden that the caregivers usually face.

The intervention takes place once a week (at the same time and day every week for each group) and lasts for one hour. Participants attend 24 video conference sessions ( 6 months). In order to examine the effectiveness of intervention, each participant is assessed before and after the 6-month period of the study. The content of the psychoeducational sessions are the same with the face to face psychoeducational group intervention. The scheduled topics of the lessons are a) Covering general information about the disease (what is dementia, what types of dementia are there, who may suffer from dementia etc.), b) behavioral problems of the PwD (which are the psychiatric and behavioral problems, what can we do about them, which drugs should we use, which non-pharmacological interventions are better etc.) and c) about the caregiver's wellness (what is the role of the caregiver, how does the caregiver feels, how important is the role of the family etc.). At the end of each lesson, the psychologist gives the opportunity to the caregivers to talk to each other and share their experience, emotions and thoughts.

Researchers have found internet-based interventions to have a positive effect in improving caregivers' mental health status and sense of self-efficacy, and reducing the lever of depression and anxiety $[5,21,22]$.

These results are also consistent with our own research. We examined two caregiver groups, an online and a face to face, which attended in a 4-month psycho-educational group intervention. Psychosocial assessment performed before and after the 4-month period of the study comprised of the following scales: Beck Depression Inventory- II - BDI-II [23], Beck Anxiety Inventory - BAI [24] and Zarit Burden Interview [25]. The within group comparison analysis have shown that both the internet-based intervention and face to face intervention reduced the level of anxiety ( $p=0.000$ and $p=0.006)$, depression ( $\mathrm{p} .000$ and p.000) and sense of burden ( $\mathrm{p}=0.000$ and $\mathrm{p}=0.013$ ). The analysis between the two groups after the intervention has shown no significant differences in levels of anxiety ( $\mathrm{p}=0.452)$, depression $(\mathrm{p}=0.692)$ and sense of burden $(\mathrm{p}=0.612)$. These results have shown that both forms of intervention are effective in improving emotional health as they reduce the level of anxiety, depression and sense of burden. So, online interventions are promising for supporting effectively and accessible the caregivers who cannot utilize traditional group interventions (unpublished data).

\section{C) Family support intervention}

When an individual is diagnosed with dementia, the whole family has to reconsider its function and its members have to redefine their personal goals and expectations [26]. A diagnosis has various consequences to the whole family as well as to each member in particular. A functional relationship among caregivers and care recipient is the key for a successful change of roles and the adaptation of the family [27]. Therefore, to face this change, a new balance should be established in the family. In order to achieve this, the support and the constant informing of the family are needed.

Family psychological support aims to help the whole family of PwD to face and cope with the disease and also, to reduce negative feelings and sense of burden. It has been found that families who participate 
Table 1: Demographics of the participants.

\begin{tabular}{|c|c|c|}
\hline Characteristics & $\begin{array}{c}\text { Experimental group } \\
(\mathbf{N}=63)\end{array}$ & $\begin{array}{c}\text { Control group } \\
(\mathbf{N}=63)\end{array}$ \\
\hline Men & 24 & 15 \\
\hline Women & 39 & 48 \\
\hline Age & $44.73(10.81)$ years & $47.76(13.26)$ years \\
\hline Education & $13.06(2.90)$ years & $12.38(3.47)$ years \\
\hline
\end{tabular}

Age \& Education scores: Means $( \pm S D)$.

Table 2: Performance of the experimental group at baseline and 12 months later.

\begin{tabular}{|c|c|c|}
\hline Measures & At baseline & $\mathbf{1 2}$ months later \\
\hline BAI & $12.33(8.56)$ & $5.50(5.83)$ \\
\hline BDI & $9.06(7.13)$ & $4.57(4.52)$ \\
\hline ZARIT & $35.06(11.92)$ & $22.12(9.18)$ \\
\hline
\end{tabular}

BAI, BDI, ZARIT scores: Means ( $\pm \mathrm{SD})$.

BAI: Beck Anxiety Inventory; BDI: Beck Depression Inventory; ZARIT: Zarit Burden Interview.

Table 3: Performance of the control group at baseline and 12 months later.

\begin{tabular}{|c|c|c|}
\hline Measures & At baseline & $\mathbf{1 2}$ months later \\
\hline BAI & $11.63(10.15)$ & $13.69(12.02)$ \\
\hline BDI & $7.88(7.70)$ & $11.55(8.92)$ \\
\hline ZARIT & $31.44(13.66)$ & $40.69(12.78)$ \\
\hline
\end{tabular}

BAI, BDI, ZARIT scores: Means ( \pm SD).

BAI: Beck Anxiety Inventory; BDI: Beck Depression Inventory; ZARIT: Zarit Burden Interview.

in a support program have a reduction of stress in comparison with control groups [28]. Moreover, it allows the members of the family to express their feelings concerning the disease and the patient [29]. Having to face a lot of duties makes the caregivers very vulnerable to various illnesses and depression. Researchers have approved those families that participate in a program of support show significant reduction of symptoms of depression after 6 months of intervention [30]. A part from the above, researchers have found that family therapy has a role in preventing caregiver's burden [31]. Finally, it improves the ability of communication between the members of the family and the PwD. A good relationship depends a lot on communication, which becomes difficult between the care recipient and the members of his/hers family. It is possible through a family support program, for the members to learn more effective ways of communication, aiming at the improvement of the quality of life of the entire family [32].

Having in mind all the above, we have developed a family support intervention, which is addressed to family members of a PwD. The goals of this intervention are the creation of more functional relationships among members of the family, emotional support, ways to deal with the change of roles and the symptoms of dementia, counselling and education on effective communication. Various techniques are used at family sessions, as representation of family communication patterns, reframing, emphasis on the differences and tasks in and out of the session.

We have contacted a pilot study in order to examine the effectiveness of the family support intervention. The study aimed to reduce negative feelings and sense of burden through family psychological support. Participants were 29 families $(63$ members, 24 men and 39 women) in an experimental group and 63 caregivers (15 men and 48 women) in a control group. Experimental group had a mean age of $44.73(\mathrm{SD}=10.81)$ years and mean years of education $13.06(\mathrm{SD}=2.90)$. The groups were matched in age $(\mathrm{p}=0.162)$, education $(\mathrm{p}=0.234)$ and gender $(\mathrm{p}=0.053)$ (Table 1). All of them were evaluated for depression by the Beck Depression Inventory (BDI), anxiety by the Beck Anxiety Inventory (BAI) and sense of burden by the Zarit Burden Interview at baseline and at the end of the intervention. The 29 families attended 24 per two weeks sessions for a period of 12 months. Sessions included education on dementia and approaches for family psychological support. Controls received no psychosocial intervention for the same period. At baseline there were no differences between the two groups in all the measures. At the end of the intervention, differences between groups appeared, in favor of the experimental group, in anxiety $(\mathrm{p}=0.00)$, depression $(\mathrm{p}=0.00)$ and burden $(\mathrm{p}=0.00)$ (Tables 2 and 3$)$. Within group analysis has shown that the experimental group reduced anxiety $(\mathrm{p}=0.00)$, depression $(\mathrm{p}=0.00)$ and burden $(\mathrm{p}=0.00)$ (Table 4). Control group showed aggravation of anxiety (p.017), depression (p.000) and sense of burden $(\mathrm{p}=0.00)$. The proposed family psychological support program has reduced negative feelings and sense of burden of the participants.

\section{D) Psychological support group}

Dementia disease affects not only the patient but it has also an immediate impact on caregivers. They are challenged even from the fist weeks after the diagnosis has been given, as many changes are taking place. Fear of unknown and numerous questions need for immediate assistance. After all, even for those caregivers who may not be surprised with particular diagnosis, the official diagnosis is still a sobering wake-up call. Caring for someone with dementia can present exhausting challenges and have significant impact on the caregiver's health. As the disease is starting to progresses, the role of the caregiver becomes gradually more demanding. Caregivers are at a great risk of developing burden, strain and depression [33].

A support group can provide assistance and guidance in these circumstances and be at help with practical instructions as: time management and stress coping situations. Alzheimer Hellas develops support groups with different targets that are fully available for caregivers. Each group is consisted of 7 to 8 caregivers, both males and females where the illness duration does not count as a barrier on the group formation either. Based on cognitive behavioral psychotherapy techniques, there are psychotherapy sessions and strategic interventions taking place $[34,35]$. There is a vast area of topics being discussed over one year of support group program. Among many, there can be mention: acceptance, burden, grief, guilty, anger, sadness, environmental support, functional problems and solutions as well as other topics the caregivers are dealing with.

Prior their enrolment, all participants are being assessed and interviewed by a psychologist who is focusing on the specific difficulties that are being faced while having the caregiver role. At the end of each year, another interview is taking place in order to measure

Table 4: Between groups difference of performance at the end of the intervention.
\begin{tabular}{|c|c|c|c|}
\hline Group & BAI & BDI & ZARIT \\
\hline Experimental group & $5.50(5.83)$ & $4.57(4.52)$ & $22.12(9.18)$ \\
\hline Control group & $13.69(12.02)$ & $11.55(8.92$ & $40.69(12.78)$ \\
\hline
\end{tabular}

BAI, BDI, ZARIT scores: Means ( \pm SD).

BAI: Beck Anxiety Inventory; BDI: Beck Depression Inventory; ZARIT: Zarit Burden Interview. 
Table 5: 5-point Likert Questionnaire Scale about the effectiveness of the intervention.

\begin{tabular}{|c|c|c|c|c|c|}
\hline Questionnaire Scale & $\begin{array}{l}\text { Very high } \\
\text { (4) }\end{array}$ & Above average (3) & $\begin{array}{l}\text { Average } \\
\text { (2) }\end{array}$ & $\begin{array}{c}\text { Below average } \\
\text { (1) }\end{array}$ & Very low (0) \\
\hline 1. Has the intervention met your initial expectations? & & & & & \\
\hline $\begin{array}{l}\text { 2. Did you find the given literature textures and poems helpful for the aims of } \\
\text { the intervention? }\end{array}$ & & & & & \\
\hline 3. Has the analysis of the textures and poems helped you? & & & & & \\
\hline 4. Has the expressive writing helped you? & & & & & \\
\hline 5. Has the intervention helped you change your feelings towards caregiving? & & & & & \\
\hline $\begin{array}{l}\text { 6. Has the intervention helped you change your feelings towards the person } \\
\text { with dementia? }\end{array}$ & & & & & \\
\hline $\begin{array}{l}\text { 7. Has the intervention helped you change your attitude in the context of } \\
\text { caregiving? }\end{array}$ & & & & & \\
\hline 8. Has the intervention helped you change your feelings towards yourself? & & & & & \\
\hline 9. Has the intervention helped you change your ways of coping as a caregiver? & & & & & \\
\hline 10. Will you continue reading literature and use expressive writing in your life? & & & & & \\
\hline 12. Did you like the expression of emotions and thoughts? & & & & & \\
\hline 13. Did you like expressive writing? & & & & & \\
\hline 14. Did you like the sharing of common experiences? & & & & & \\
\hline 15. Did you find hard to understand the given literature textures and poems? & & & & & \\
\hline 16. Did you find hard to express your thoughts and emotions? & & & & & \\
\hline 17. Did you find hard to write stories following expressive writing? & & & & & \\
\hline 18. Did you find hard the sharing of common experiences? & & & & & \\
\hline
\end{tabular}

Table 6: Effectiveness of the intervention.

\section{Questions}

1. Has the intervention met your initial expectations?

2. Did you find the given literature textures and poems helpful for the aims of the intervention?

3. Has the analysis of the textures and poems helped you?

4. Has the expressive writing helped you?

5. Has the intervention helped you change your feelings towards caregiving?

6. Has the intervention helped you change your feelings towards the person with dementia?

7. Has the intervention helped you change your attitude in the context of caregiving?

8. Has the intervention helped you change your feelings towards yourself?

9. Has the intervention helped you change your ways of coping as a caregiver?

10. Will you continue reading literature and use expressive writing in your life?

11. Did you like the given literature textures and poems?

12. Did you like the expression of emotions and thoughts?

13. Did you like expressive writing?

14. Did you like the sharing of common experiences?

15.Did you find hard to understand the given literature textures and poems?

16. Did you find hard to express your thoughts and emotions?

17. Did you find hard to write stories following expressive writing?

18. Did you find hard the sharing of common experiences?

$\mathrm{F}=$ frequency; $\mathrm{P}=$ valid percent $\%$

the potential progress.

This is indeed for most of them the only time that they are away from the responsibility of caregiving. Adding up, this represents a

\begin{tabular}{|c|c|c|c|c|c|c|c|c|c|}
\hline \multicolumn{2}{|c|}{4} & \multicolumn{2}{|c|}{3} & \multicolumn{2}{|c|}{$\mathbf{2}$} & \multicolumn{2}{|c|}{1} & \multicolumn{2}{|c|}{0} \\
\hline 13 & $72 ., 2 \%$ & 4 & $22.2 \%$ & 0 & 0 & 1 & $5.6 \%$ & 0 & 0 \\
\hline 13 & $72.2 \%$ & 5 & $27.8 \%$ & 0 & 0 & 0 & 0 & 0 & 0 \\
\hline 14 & $77.8 \%$ & 4 & $22.2 \%$ & 0 & 0 & 0 & 0 & 0 & 0 \\
\hline 12 & $66.7 \%$ & 5 & $27.8 \%$ & 1 & $5.6 \%$ & 0 & 0 & 0 & 0 \\
\hline 11 & $61.1 \%$ & 4 & $22.2 \%$ & 2 & $11.1 \%$ & 0 & 0 & 1 & $5.6 \%$ \\
\hline 9 & $50 \%$ & 4 & $22.2 \%$ & 3 & $16.7 \%$ & 1 & $5.6 \%$ & 1 & $5.6 \%$ \\
\hline 11 & $61.1 \%$ & 3 & $16.7 \%$ & 3 & $16.7 \%$ & 0 & 0 & 1 & $5.6 \%$ \\
\hline 13 & $72.2 \%$ & 3 & $16.7 \%$ & 2 & $11.1 \%$ & 0 & 0 & 0 & 0 \\
\hline 9 & $50 \%$ & 8 & $44.4 \%$ & 1 & $5.6 \%$ & 0 & 0 & 0 & 0 \\
\hline 9 & $50 \%$ & 7 & $38.9 \%$ & 1 & $5.6 \%$ & 1 & $5.6 \%$ & 0 & 0 \\
\hline 12 & $66.7 \%$ & 6 & $33.3 \%$ & 0 & 0 & 0 & 0 & 0 & 0 \\
\hline 14 & $77.8 \%$ & 4 & $22.2 \%$ & 0 & 0 & 0 & 0 & 0 & 0 \\
\hline 12 & $66.7 \%$ & 5 & $27.8 \%$ & 1 & $5.6 \%$ & 0 & 0 & 0 & 0 \\
\hline 14 & $77.8 \%$ & 3 & $16.7 \%$ & 1 & $5.6 \%$ & 0 & 0 & 0 & 0 \\
\hline 0 & 0 & 0 & 0 & 1 & $5.6 \%$ & 3 & $16.7 \%$ & 14 & $77.8 \%$ \\
\hline 2 & $11.1 \%$ & 1 & $5.6 \%$ & 1 & $5.6 \%$ & 5 & $27.8 \%$ & 9 & $50 \%$ \\
\hline 0 & 0 & 3 & $16.7 \%$ & 1 & $5.6 \%$ & 6 & $33.3 \%$ & 8 & $44.4 \%$ \\
\hline 1 & $5.6 \%$ & 1 & $5.6 \%$ & 2 & $11.1 \%$ & 2 & $11.1 \%$ & 12 & $66.7 \%$ \\
\hline
\end{tabular}

great opportunity for all members to break up the routine and have some social interaction. The program is hosting a resourceful sharing environment of information, insight, advice and encouragement which provides the perfect opportunity to learn from each other's 
experiences while everybody is sharing the same main challenge.

Furthermore, the support group has a great impact on caregivers' health and helps improving their overall quality of life meanwhile is essential to facilitate their role and reduce the likelihood of institutionalization. Joining a support group is important for caregivers as it is an opportunity to improve their knowledge about dementia, to gain realistic expectation about the disease, to develop effective coping skills, to handle their negative thoughts and feelings, and reinforce their sense of caring capacity.

To sum up, anxiety and depression are reduced and the sense of burden diminished while anger, loneliness and loss are being effectively treated $[36,37,38]$.

\section{E) Support group using literature entitled "Listen to my story"}

Caregivers of PwD experience a variety of feelings concerning their role and their daily life tasks [39]. Personal limitations and the environment itself makes it difficult for them to express their feelings to their social network or even on a classic support group, where oral speech is the main tool of expression. It has been found that art can serve as a means for the caregivers to externalize their feelings [40].

Art in general and creative arts-based interventions for caregivers are well known for their therapeutic effects, as shown by numerous studies. For instance, art and music therapy have a positive effect in enhancing self-care [41], expressive writing helps caregivers to adjust in a more efficient way in their role [42], as well as it helps reducing anxiety and improves general health [43]. Moreover, poetry reading enhances wellbeing, while the creation of poetry improves communication skills [44].

Based on this background, the last three years the Unit of Caregivers has developed a support group using poetry and literature. Narration and expressive writing are the creative tools used to help families of people with dementia to express their feelings, to render their experiences meaningful and to familiarize themselves with "their condition" [45]. Through literature and poetry caregivers can exchange thoughts and experiences and gather answers to their questions concerning dementia and conceive caregiving from a new perspective.

The group meets with two expert psychologists once a week, in the same time and day every week, and each session lasts 90 minutes. On each session, caregivers are given a text literature or a poem and they share thoughts and feelings that arise spontaneously. After this, they are asked to associate arising feelings (for example sadness, satisfaction, stress, anger, happiness) with something that they have felt or experience in their daily life with the PwD. At the end of each session, caregivers write their own stories using expressive and spontaneous writing techniques.

An attempt to mingle all these stories in a single one and then dramatize it with the help of two professional actors has been made. In the conference "Caring for the caregivers" which took place in Thessaloniki on the 18-20/03/2016, participants had a brief experience of it, as a part of a workshop. The complete version of caregivers' stories was shown live in an audience on 21 March 2017 with the help of three professional actors and a caregiver/amateur actor.
We have conducted a pilot study with a group of caregivers, who attended this intervention for a year (30 sessions), in order to examine its effectiveness. Participants were 18 caregivers of $\mathrm{PwD}, 15$ (83. 3\%) women and $3(16.7 \%)$ men. Mean age was $60.67( \pm 7.04)$ years old and mean years of education $15.50( \pm 2.62)$. Their family status was as follow: 10 married (55.6\%), 4 unmarried (22.2\%), 2 divorced (11.1\%) and 2 widows (11.1\%). As far as it concerns the relationship with the PwD, 5(27. 8\%) were spouses, $12(66.7 \%)$ were children and $1(5.6 \%)$ was sibling. Eleven (11) caregivers lived with the patient, while 7 lived separate.

Participants answered at the end of the intervention a 5-point Likert Scale (Very High, Above Average, Average, Below Average and Very Low) questionnaire, (a total of 18 questions) about the effectiveness of the group (Table 5). The results (Table 6) showed that the majority of caregivers have found the intervention very helpful concerning their attitude towards caregiving (61.1\%), the PwD (50\%), the way they cope with difficult situations (50\%) and the way they feel about theirselves (72.2\%). Moreover, participants have found the given literature texts and poems helpful (72.2\%) and the intervention has met their initial expectations (72.2\%). The activities liked the most were the expression of their emotions and thoughts (77.8\%) and the sharing of common experiences (77.8\%). Finally, the majority of the participants didn't have difficulties in any part of the intervention, although some of them were unclear about expressive writing (16.7\%).

Limitations of the study are the small size of the sample and the lack of control group. Further research should be done on this field in order to generalize our results and to study in depth the effectiveness of literature reading and expressive writing in caregivers of PwD. Finally, we could investigate the effectiveness of watching or participating in a theatre piece in the context of dementia and caregiving, as it was held in March 2017 in Thessaloniki, when the stories of caregivers were presented in an audience of patients, of caregivers and friends of Alzheimer Hellas.

Considering the above, a group intervention based on literature and expressive writing is efficient for caregivers of $\mathrm{PwD}$, as it represents a different form of expression and sharing their emotions. Additionally, it helps them change the way they feel towards dementia, caregiving, the PwD and theirselves.

\section{F) "Theater of the oppressed"}

Hardships faced by PwD are directly linked with their family members' daily duties. As the time passes by, so the degree of illness decays which means increasingly more effort made by caregivers. The Theater of Compassion/Oppression is an aesthetic method created by the Brazilian author Augusto Boal (1960), which aims to promote social change. Boal was influenced by the work of educational and theorist Paulo Freire. Boal's techniques are used as a means to promote social and political change. At the Theater of the Compressed, the audience becomes active. Viewers become actors, "spectators" become "spectators" and explore, show, analyze, transform, change the reality they live in.

This particular program is being used as a primer therapy tool in the fallowing intervention. Titled "the theater of the oppressed", it aims to help caregivers with the demanding role they have been 
assigned with, being mainly focused on stress management and the feeling of burden. Furthermore:

-The theater brings concrete applications. Whatever is being learned are trough practical exercises and not trough theoretical lectures.

-Theater may help challenge and unveil the unknown potential within self.

- Theater is an accessible tool as it can be easily found within each person.

Cases:

- Creativity and active participation will help caregivers feel relieved which will forward them to innovative problem-solving methods.

- Game interaction is going to help restoring dialogue and provide a perfect environment for feelings expression.

- The overall challenge would rather be to develop the ability of creative daily problem-solving skill.

- It will reduce psychological fatigue as a whole (stress, depression).

The intervention consists of 1 hour weekly meetings for over 6 months. The program is divided into 2 phases.

First phase: During the sessions, the psychologist is first investigating the main source of psychological burden that caregivers bear and it is often found that oppression is the main source. Prior, a play is being developed. The scenario presents the protagonist (caregiver) in various circumstances of his life: verbally connecting or physically caring with/for the patient. The main character(caregiver) is also being presented in conflict situations with the others nearby: his tendency to abandon the patient, the disagreements brought by siblings, and also in conflict with his own health and social struggles.

After all the caregivers went through first stage, sharing their experiences and feelings, the script for each person is briefly being constructed and organized. Each story that is going to be played will have another protagonist than the real teller. Therefore, when the play is taking place, each caregiver is able to rationally observe as a spectator their behavior. They are given the opportunity to judge and criticize the play and gradually this is how drama therapy takes place. Acceptance, growing, change and problem solving skills are subsequently developed.

Second phase: The show is presented to the public, e.g. In the framework of a workshop on the treatment of $\mathrm{PwD}$, an event on dementia, etc. The presentation of the show depicts live on the scene all that relates to surveys, tables and statistical data on patient care. The experience of the caregiver unfolds on the stage and the public is invited to intervene by giving solutions.

The show is played by the participants of the group, in which the protagonist (caregiver) acquires the role of the oppressed, while the "competitors" (patient, relatives, doctors etc.) are the oppressors. When the show ends, the "mediator-animator", a psychologist, announces that the show will repeat itself and urges the spectators to locate the oppression, in whatever form it may appear.
The person who identifies it has the right to stop the performance and undertake the lead of "competitors", to propose solutions or express thoughts or to devise another role. Therefore, Theater of the Compassion engages the viewer by giving him a voice and puts him at the center of the theatrical act, helping this way the boundaries between the scene and the audience to break.

The play finishes with a new version of the script inspired by all the suggestions that have been made. Now is when the teller (caregiver) is able to come out of the stalemate and the discussion starts.

\section{G) Relaxation intervention}

Relaxation intervention is provided to caregivers who, according to Beck Anxiety Inventory -BAI, have high anxiety psychosomatic symptoms. Anxiety causes a cognitive, behavior and psychophysiological response and leads to a state of alert. If it is high intense and long term then the consequences to human body will be negative. Relaxation is a process that decreases the effects of stress on our mind and body [46,47]. The relaxation intervention aims to reduce anxiety level and manage psychosomatic symptoms to participants using the therapeutic techniques of (a) Progressive Muscle Relaxation [48], (b) diaphragmatic breathing exercises [49] and (c) guided imagery [50]. Relaxation techniques help them to recognize anxiety symptoms on their body and influence improvements through changes in the cardiovascular and muscular system as well as in central autonomic system [51].

Progressive Muscle Relaxation techniques help to focus the attention on the body, identify tension in the different parts, realize the difference between tension and relaxation in the muscle and lead the body in relaxation state.

Diaphragmatic breathing exercises are based on deep breathing and inhalation using diaphragm in order to oxygenate the body and activate the parasympathetic nerve. Diaphragmatic breathing helps the caregivers control their breath, reduce psychosomatic symptoms and lower the body's state of alert.

Guided imagery helps the participants, following the verbal instructions of the therapist, to concentrate on their mind and visualize a positive image. This technique helps the caregivers diminish the negative or dysfunctional thoughts and replace them with positive. Moreover, they can find solutions to their difficulties concerning the caregiving or their personal life and adopt another point of view.

Relaxation program is weekly and lasts for 1 hour. It is a complementary intervention and it is always provided in combination with a therapeutic intervention such as support group or psychoeducational group.

\section{H) Grief support group}

Grief support group refers to bereaved dementia caregivers who experience the loss of their relatives. Grief is a normal and unique human experience, so the purpose of the support group is not to cure the grief. It rather aims to facilitate the grief process and prevents from clinical depression and complicated grief. According to Holland et al. [52], about $20 \%$ of dementia caregivers experience complicated grief after physical death of care recipient. Moreover, in the first year after the loss, $30 \%$ of caregivers are at risk of clinical depression [53]. 
Table 7: 4-point Likert Questionnaire Scale about the effectiveness of the intervention.

\begin{tabular}{|c|c|c|c|c|}
\hline Questionnaire Scale & Poor & Adequate & Good & Excellent \\
\hline Did the intervention meet your initial expectations? & 1 & 2 & 3 & 4 \\
\hline Did the intervention help you to accept the loss of your relative? & 1 & 2 & 3 & 4 \\
\hline Did the intervention help you to develop new ways of coping with the difficulties you were experiencing? & 1 & 2 & 3 & 4 \\
\hline Did the intervention help you manage your feelings about the loss? & 1 & 2 & 3 & 4 \\
\hline Did the intervention help you to express/share your feelings with the important persons in your life? & 1 & 2 & 3 & 4 \\
\hline
\end{tabular}

Table 8: Means and Standard Deviation between the two assessments.

\begin{tabular}{|c|c|c|}
\hline & Pre-Intervention & Post- Intervention \\
\hline BAI & $13.15(8.6)$ & $5.53(4.96)$ \\
\hline BDI & $18.92(10.30)$ & $9.00(10.70)$ \\
\hline PSS & $20.08(7.08)$ & $12.61(7.44)$ \\
\hline
\end{tabular}

BAI, BDI, PSS scores: Means ( \pm SD).

BAI: Beck Anxiety Inventory; BDI: Beck Depression Inventory; PSS: Perceived Stress Scale.

In the context of group safety and acceptance, the participants have the opportunity to share their feelings and thoughts about their grief. Discussing with other people who experience the same feelings, they are more comfortable to talk about loneliness, depression, guilt ("Have I done enough?") and regret ("Was it a good decision for my relative?") [54]. Recalling the narrative of death, bereaved caregivers can reconstruct the meaning of grief and embrace its meaning into their day to day life [55]. Reconstructing the meaning of grief, give them the capability to redefine their personal identity in the context of loss [56].

The present grief support group aims to help the bereaved dementia caregivers to accept the reality of loss, manage their emotions and adapt it to a new lifestyle. The program consists of 16 weekly sessions (duration 60 minutes) and lasts for 4 months. The sessions follow the thematic bellow:

a) What does support means for them. Sources of support in this period of their life.

b) Discussion about grief. Recognition of the chances from their lives (practical, emotional and role-play exercises). What changed and what remain the same. Ways of coping.c) Emotional relationship with their beloved. How do they maintain their memory and relationships?

d) Death as existential landmark. How is life perceived through the experience of mourning?

e) Unfinished business.

f) Transition- grief brings change. How can they continue life without their beloved one? Acceptance and adjustment.

In a pilot study, we examined 13 participants from the intervention group. Participants were assessed before and after a 4-month period by using the following scales: Beck Depression Inventory- II - BDIII [23], Beck Anxiety Inventory - BAI [24] and Perceived Stress Scale- PSS [57]. At the end of the intervention they also answered a 4-point Likert Scale (Poor, Adequate, Good, Excellent) questionnaire consisting in 5 questions about the effectiveness of the group (Table $7)$.

The mean age of the participants was 53 years (range 37-66 years).
There was 1 male participant and 12 female participants. Four of them were spouse caregivers and 8 were adult children caregivers.

The Wilcoxon analysis has shown significant differences between the initial and after the intervention assessment in levels of psychosomatic anxiety symptoms (BAI) (p.003), depression symptoms (BDI) (p.002) and cognitive perceived anxiety symptoms (PSS) $(\mathrm{p}=0.010)$. The mean score has shown that after the intervention participants were experiencing fewer depression symptoms and lower cognitive and psychosomatic anxiety symptoms (Table 8).

Frequencies analysis has been used in order to examine the 4-point Likert Questionnaire Scale about the effectiveness of the intervention. In first question "Did the intervention meet your initial expectations?" all the participants $(\mathrm{n}=13)$ marked "excellent" (100\%). In second question "Did the intervention help you to accept the loss of your relative?" 10 participants noted "excellent" (76.9\%) and 3 participants noted "good" (23.1\%). In third question "Did the intervention help you to develop new ways of coping with the difficulties you were experiencing?" Seven (7) participants marked "excellent" (53.8\%) and 6 marked "good" (46.2\%). In forth question "Did the intervention help you manage your feelings about the loss?" eleven (11) participants noted "excellent" (84.6\%) and 2 noted "good" (15.4\%). In fifth question "Did the intervention help you to express/ share your feelings with the important persons from your life? Nine (9) participants noted "excellent" (69.2\%), 3 participants "good" (23.1\%) and 1 participant "adequate" (7.7\%) (Table 9) (unpublished data).

In conclusion, the results have shown that the intervention helped all the participants to accept the loss of their beloved one, to develop new ways of coping, to manage their grief and to share these feelings with the close persons from their life. Moreover, after the intervention, all the participants presented lower depression and anxiety symptoms.

The limitations of the present pilot study are a) the small size of the participant sample, b) the lack of control group and c) the lack of a grief scale measure. Taking into consideration the above limitations, further research is needed to evaluate the efficacy of the grief support group for bereaved dementia caregivers.

\section{I) Community outreach}

Intervention for children entitled “Who I am grandpa?": As the rates of dementia patients are constantly increasing, more and more children are expected to come in contact with grandparents with dementia [58]. In many families there is a perception that children are not able to understand the various health issues that arise and that it is good to protect them from such information as they may be afraid or embarrassed. So there is no particular space or time for children to express their questions and feelings about their beloved grandparent 
Table 9: Frequency and Valid Percent of 4-point Likert Questionnaire Scale about the effectiveness of the intervention.

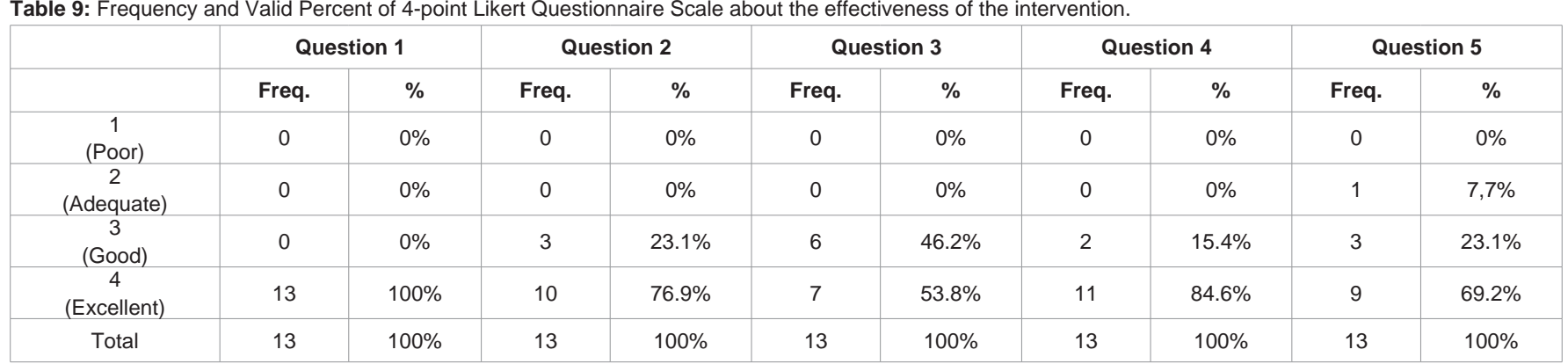

[59]. As a result, children can not understand the symptoms of the disease and they explain the strange behavior of the grandparents as lack of love. Moreover, they want to spend less time with their grandparents, feel emotionally away from them and are ashamed to talk about them with their friends [60].

Children's attitude towards $\mathrm{PwD}$ can be changed through specialized interventions that can help them to understand the symptoms of the disease and learn new ways of connecting with their grandparents [61]. Psychotherapeutic interventions give the opportunity to get in touch with other children who have a grandparent with dementia. This helps them to feel comfortable sharing their experience.

Three psychologists of Alzheimer Hellas have conceived and realized the intervention entitled "Who am I, grandpa?". It is taking place either in Elementary schools in order to raise children's awareness of dementia or in the framework of Alzheimer Hellas in order to inform grandchildren (6-12 years old) about PwD. The intervention has been attended by 110 children. It is a 3 hours group intervention that aims to help children understand the symptoms and causes of dementia in order to prepare them to cope with the change of attitude of their grandparents and find new methods of interaction with them. Through a vast amount of experiential techniques such as fairy tales, photos, collages, painting and group games, the children are given the opportunity to express their feelings and thoughts. Additionally, they become aware of dementia which reduces social stigma.

Simultaneously, the parents were held in order to make them familiar with the disease and the way they should communicate and approach their children. Parents also shared and discussed the difficulties they were facing regarding their children's behavior.

After the end of the intervention, a written assessment has been done by the children. They responded that the intervention helped them to learn about dementia (definition, symptoms and treatment of the disease) and it also answered many of their questions. Through the game they realized the feelings of their grandparents with dementia, expressed their own feelings and shared similar experiences with other children. Also, they developed useful methods of connecting with their grandparents.

Two months after the program, a meeting has been held with the parents in order to record the long-term results of the intervention for both their children and themselves.

As far as it concerns the children, parents mentioned that they wanted to spend more time with their grandparents and they developed creative activities such as games, music or a walk. Moreover, they felt less angry about the symptoms of dementia such as the repetition of questions and they advised their parents about the way they should cope with their grandparents. Overall, they were feeling free to express their thoughts and their feelings. Specifically, a child wrote a poem about his grandmother and read it in his class.

As far as it concerns them, the parents said that they understood the symptoms of the disease, they have developed more effective ways of coping with the PwD and they have improved the communication with their children.

In conclusion, the intervention helped the children to learn about dementia and how to accept and cope with it, to share their feelings and to maintain a better connection with their grandparents. In addition, children have taught us that a) they learn and understand easily, b) they are flexible in finding solutions and alternative ways of coping in everyday problems and c) sometimes they have more realistic approach than the adults.

Radio program "All about dementia": "All about dementia” is a radio program which has derived from the cooperation between Alzheimer Hellas and Municipal Voluntary Radio of Thessaloniki, Greece. Three psychologists of Alzheimer Hellas are in charge for this project and also the hosts of the radio program which lasts for an hour and is aired 3 times per month.

Dementia is a multidimensional disease. Not only the patients but also the caregivers face emotional, practical and social consequences which makes the information on prevention, coping and treatment delivery crucial. These are the exact main topics that this radio program covers. During the radio program, which is the first of its kind in Greece, the psychologists give information regarding dementia, provide counselling advices for caregivers and share the latest research on therapy and various ways of preventing dementia. Professionals of health such as neurologists, psychologists, fitness instructors or care workers are regularly invited to the show to share their knowledge and clinical experience. Caregivers, as well as patients with dementia, are often interviewed and their voices, feelings and thoughts are being publicized which has a great impact on for the general public.

Moreover, radio program "All about dementia" aims to provide counselling support to caregivers from different cities that cannot benefit from the traditional support services, due to health issues, transportation and time constraints. Apart from the educational focus on dementia, our goal is to emphasize that in the journey of dementia "you are not alone". 


\section{Conclusion}

The therapeutic interventions provided by Day Center for Caregivers of Alzheimer Hellas have been based on international literature and have been tailored to caregivers' psychological needs. The results of our studies have shown effectiveness in emotional state and sense of burden of the participants. Future research is needed to evaluate the efficacy of these interventions in larger sample of caregivers.

\section{References}

1. World Alzheimer Report. Alzheimer's Disease International. 2016.

2. Dementia: a public health priority. World Health Organization. 2012

3. Brodaty H, Donkin M. Family caregivers of people with dementia. Dialogues in Clinical Neuroscience. 2009; 11: 217-228.

4. Report from a National Consensus Development Conference. Family Caregiver Alliance. Caregiver Assessment: Principles, Guidelines and Strategies for Change. 2006.

5. Marziali E, Garcia LJ. Dementia Caregivers' Responses to 2 Internet-Based Intervention Programs. American Journal of Alzheimer's Disease \& Other Dementias. 2011; 26: 36-43.

6. Blom M, Bosmans J, Culpers P, Zarit S, Pot M. Effectiveness and costeffectiveness of an internet intervention for family caregivers of people with dementia: design of a randomized controlled trial. BMC Psychiatry. 2013; 13 : 17.

7. Vandepitte S, Van Den Noortgate N, Putman K, Verhaeghe S, Faes K, Annemans L. Effectiveness of supporting informal caregivers of people with dementia: a systematic review of randomized and non-randomized controlled trials. Journal of Alzheimers Disease. 2016; 52: 929-965.

8. Pfeiffer K, Hautzinger M, Patak M, Grünwald J, Becker C, Albrecht D. Problem-solving in caregiver-counselling (PLiP Study): study protocol of a cluster randomized pragmatic trial. BMC Geriatrics. 2017; 17: 64.

9. van der Lee J, Bakker TJEM, Duivenvoorden HJ, Dröes RM. Do determinants of burden and emotional distress in dementia caregivers change over time? Aging \& Mental Health. 2017; 21: 232-240

10. van der Lee J, Bakker TJEM, Duivenvoorden HJ, Dröes RM. Multivariate models of subjective caregiver burden in dementia: A systematic review. Ageing Research Reviews. 2014; 15: 76-93.

11. Sörensen S, Pinquart M, Duberstein P. How effective are interventions with caregivers? Anupdatedmeta-analysis. The Gerontologist. 2002; 42: 356-372.

12. Wang LQ, Chien WT. Randomised controlled trial of a family-led mutual support programme for people with dementia. Journal of clinical nursing. 2011; 20: 2362-2366

13. Judge KS, Bass DM, Snow AL, Wilson NL, Morgan R, Looman WJ, et al Partners in Dementia Care: A Care Coordination Intervention for Individuals with Dementia and Their Family Caregivers. The Gerontologist. 2011; 51: 261-272.

14. Pendergrass A, Becker C, Hautzinger M, Pfeiffer K. Dementia caregiver interventions: a systematic review of caregiver outcomes and instruments in randomized controlled trials. International Journal of Emergency Mental Health and Human Resilience. 2015; 17: 459-468.

15. Brooks D, Fielding E, Beattie E, Edwards $H$, Hines S. Effectiveness of psychosocial interventions on the psychological health and wellbeing of family carers of people with dementia following residential care placement: a systematic review protocol. JBI Database of Systematic Reviews and Implementation Reports. 2017; 15: 1228-1235.

16. Joling KJ, van Marwijk HW, Smit F, van der Horst HE, Scheltens $P$, van de Ven PM, et al. Does a family meetings intervention prevent depression and anxiety in family caregivers of dementia patients? A randomized trial. PLoS One. 2012; 7: e30936.
17. Chiu T, Marziali E, Colantonio A, Carswell A. Internet-Based Caregiver Support for Chinese Canadians Taking Care of a Family Member with Alzheimer Disease and Related Dementia. Canadian Journal on Aging. 2009; 28: 323-336.

18. Seike A, Sumigaki C, Takeda A, Endo H, Sakurai T, Toba K. Developing an interdisciplinary program of educational support for early-stage dementia patients and their family members: An investigation based on learning needs and attitude changes. Geriatrics Gerontology. 2014; 14: 28-34.

19. Hsu CC, Wang YM, Huang CR, Sun FJ, Lin JP. Sustained Benefit of a Psycho-educational Training Program for Dementia Caregivers in Taiwan. International Journal of Gerontology. 2017; 11: 31-35

20. Kales HC, Gitlin LN, Stanislawski B, Marx K, Turnwald M, Watkins DC, et al. The Development of a Caregiver- focused, Web-based Program to Assess and Manage Behavioral and Psychological Symptoms of Dementia. Alzheimer Disease Associated Disorders. 2016; DOI: 10.1097/ WAD.0000000000000177.

21. Blom MM, Zarit SH, Zwaaftink RBMG, Cuijpers P, Pot AM. Effectiveness of an Internet Intervention for Family Caregivers of People with Dementia: Results of a Randomized Controlled Trial. PLOS ONE. 2015; 10: e0116622.

22. Beauchamp N, Irvine BA, Seeley J, Johnson B. Worksite-Based Internet Multimedia Program for family caregivers of persons with dementia. The Gerontologist. 2005; 45: 793-801.

23. Beck AT, Steer RA, Brown GK. The Beck Depression Inventory Second Edition Manual. San Antonio: Psychological Corporation. 1996.

24. Beck AT, Epstein N, Brown G, Steer RA. An inventory for measuring clinical anxiety: psychometric properties. Journal of consulting and clinical psychology. 1988; 56: 893-897.

25. Zarit SH, Reever KE, Bach-Peterson J. Relatives of the impaired elderly: correlates of feelings of burden. The Gerontologist. 1980; 20: 649-655.

26. Qualls SH, Anderson LN. Family therapy in late life. Psychiatric Annals. 2009; 39: $844-850$.

27. Heller T, Gibbons HM, Fisher D. Caregiving and Family Support Interventions: Crossing Networks of Aging and Developmental Disabilities. Intellectual and Developmental Disabilities. 2015; 53: 329-345.

28. Russel CD. The cost-effectiveness of family therapy: a summary and progress report. Journal of Family Therapy. 2008; 30: 399-410.

29. Brody SJ, Poulshock SW, Masciocchi CF. The family caring unit: a major consideration in the long-term support system. The Gerontologist. 1978; 18: 556-561.

30. Eisdorfer C, Czaja SJ, Loewenstein DA, Rubert MP, Arguelles S, Mitrani VB, et al. The Effect of a Family Therapy and Technology-Based Intervention on Caregiver Depression. The Gerontologist. 2003; 43: 521-531.

31. Tremont G, Duncan JD, Bishop DS. Unique Contribution of Family Functioning in Caregivers of Patients with Mild to Moderate Dementia. Dementia and Geriatric Cognitive Disorders. 2006; 21: 170-174.

32. Dooley NR, Hinojosa J. Improving quality of life for persons with Alzheimer's disease and their family caregivers: brief occupational therapy intervention. American Journal of Occupational Therapy. 2004; 58: 561-569.

33. Connell CM, Janevic MR, Gallant MP. The costs of caring: impact of dementia on family caregivers. Journal of psychiatry and neurology. 2001; 14: 179-187.

34. Mitrani VB, Lewis JE, Feaster DJ, Czaja SJ, Elsdorfer C, Schulz R, et al. The role of family functioning in the stress process of dementia caregivers. Gerontologist. 2006; 46: 97-105.

35. Secker DL, Brown RG. Cognitive behavioral therapy (CBT) foe caregivers of patients with Parkinson's disease: a preliminary randomized trial. Journal of neurology, neurosurgery, and psychiatry. 2005; 76: 491-497.

36. Chu $\mathrm{H}$, Yang $\mathrm{CY}$, Liao $\mathrm{YH}$, Chaing $\mathrm{LI}$, Chen $\mathrm{CH}$, Lin $\mathrm{CC}$, et al. The effects of support group on dementia caregivers' burden and depression. Journal of Aging and Health. 2010; 23: 228-241.

37. Karagiozi K, Papaliagkas V, Giaglis G, Papastavrou E, Pattakou V, Tsolaki M. 
Combined intervention for caregivers of patients with dementia: a randomized controlled trial. International Journal of Academic Research in Psychology. 2014; 1: 77-91.

38. Mittelman M, Roth DL, Coon DW, Haley WE. Sustained benefit of supportive intervention for depressive symptoms in caregivers of patients with Alzheimer's disease. The American Journal of Psychiatry. 2004; 161: 850 856.

39. Richardson TJ, Lee SL, Berg-Weger M, Grossberg GT. Caregiver health: Health of caregivers of Alzheimer's and other dementia patients. Current Psychiatry Reports. 2013; 15: 367.

40. Butcher HK, Gordon JK, Ko JW, Perkhounkova Y, Cho JY, Rinner A, et al. Finding Meaning in Written Emotional Expression by Family Caregivers of Persons With Dementia. American Journal of Alzheimer's Disease \& Other Dementias. 2016; 31: 631-642.

41. Murrant GM, Rykov M, Amonite D, Loynd M. Creativity and self-care for caregivers. Journal of Palliative Care. 2000; 16: 44-49.

42. Caldwell R. Literature review-Theory: At the confluence of memory and meaning - Life review with older adults and families: Using narrative therapy and the expressive arts to re-member and re-author stories of resilience. Family Journal. 2005; 13: 172-175.

43. Mackenzie CS, Wiprzycka UJ, Hasher L, Goldstein D. Does expressive writing reduce stress and improve health for family caregivers of older adults? The Gerontologist. 2007; 47: 296-306.

44. Swinnen A. Healing words: a study of poetry interventions in dementia care. Dementia. 2014; 27: 1377-1404.

45. Baikie KA, Wilhem K. Emotional and physical health benefits of expressive writing. Advances in Psychiatric Treatment. 2005; 11: 338-346.

46. Tsitsi T, Charalambous A, Papastavrou E, Raftopoulos V. Effectiveness of a relaxation intervention (progressive muscle relaxation and guided imagery techniques) to reduce anxiety and improve mood of parents of hospitalized children with malignancies: A randomized controlled trial in Republic of Cyprus and Greece. European Journal of Oncology Nursing. 2017; 26: 9-18.

47. Aiger M, Palacin M, Pifarré P, Llopart M, Simó M. Effectiveness of relaxation techniques before diagnostic screening of cancer patients. Suma Psicológica. 2016; 23: 133-140.

48. Jacobson E. Progressive Relaxation. $2^{\text {nd }}$ edn. Chicago: Chicago Press. 1938.
49. Ernst E. Breathing techniques--adjunctive treatment modalities for asthma? A systematic review. The European Respiratory Journal. 2000; 15: 969-972.

50. Achterberg J. Imagery in healing: Shamanism and modern medicine. Boston: Shambhala/New Science Library. 1985.

51. Gonzalez JS. Estudiocuasi-experimental sobre las terapias de relajacionenpacientes con ansiedad. Revista Electronica Trimestral de Enfermeria. 2012; 11: 39-53.

52. Holland JM, Currier JM, Gallagher-Thompson D. Outcomes from the resources for enhancing Alzheimer's caregiver health $(\mathrm{REACH})$ program for bereaved caregivers. Psychology and Aging. 2009; 24: 190-202.

53. Schulz R, Boerner K, Shear K, Zhang S, Gitlin LN. Predictors of complicated grief among dementia caregivers: A prospective study of bereavement. American Journal of Geriatric Psychiatry. 2006; 14: 650-658.

54. Supiano KP, Haynes LB, Pond V. The process of Change in Complicated Grief Group Therapy for Bereaved Dementia Caregiver: An Evaluation Using the Meaning of Loss Codebook. Journal of Gerontological Social Work. 2017; 60: 155-169.

55. Neimeyer RA. Techniques of grief therapy. New York: Routledge Books. 2012.

56. Hibberd R. Meaning reconstruction in bereavement: Sense and significance. Death Studies. 2013; 37: 670-692.

57. Cohen S, Kamarck T, Mermelstein R. A global measure of perceived stress. Journal of Health and Social Behavior. 1983; 24: 386-396.

58. Celdran M, Triado C, Villar F. "My grandparent has dementia": how adolescents perceive their relationship with grandparents with a cognitive impairment. Journal of Applied Gerontology. 2010; 30: 332-352.

59. Sakai EY, Carpenter BD, Rieger RE. "What's wrong with grandma?": depictions of Alzheimer's disease in children's storybooks. American Journal of Alzheimer's Disease\& Other Dementias. 2012; 27: 584-591.

60. Fuh JL, Wang SJ, Juang KD. Understanding of senile dementia by children and adolescents: why grandma can't remember me? ActaNeurologicaTaiwanica. 2005; 14: 138-142.

61. Gigliotti C, Morris M, Smock S, Jarrott SE, Graham B. An Intergenerational Summer Program Involving Persons with Dementia and Preschool Children, Educational Gerontology. 2005; 31: 425-441.
J Fam Med - Volume 4 Issue 5 - 2017

ISSN : 2380-0658 | www.austinpublishing group.com

Karagiozi et al. (C) All rights are reserved
Citation: Karagiozi K, Margaritidou P, Egkiazarova M, Toumpalidou M, Makri M and Tsolaki M. Interventions for Caregivers of People with Dementia in Greece. J Fam Med. 2017; 4(5): 1125. 